\title{
Hypoxia, Snail and incomplete epithelial-mesenchymal transition in breast cancer
}

\author{
K Lundgren ${ }^{1,4}$, B Nordenskjöld ${ }^{2,3}$ and G Landberg*, 1,4 \\ 'Department of Laboratory Medicine, Center for Molecular Pathology, Malmö University Hospital, Lund University, Malmö SE-205 02, Sweden; \\ ${ }^{2}$ Department of Oncology, Borås Hospital, Borås SE-501 82, Sweden; ${ }^{3}$ Division of Oncology, Faculty of Health Sciences, Linköping University, Linköping \\ SE-58I 85, Sweden and ${ }^{4}$ Breakthrough Breast Cancer Research Unit, School of Cancer, Enabling Sciences and Technology, The University of Manchester, \\ Manchester Academic Health Science Centre, Paterson Institute for Cancer Research, The Christie NHS Foundation Trust, Wilmslow Road, Manchester \\ M20 4BX, UK
}

BACKGROUND: Hypoxia is an element of the tumour microenvironment that impacts upon numerous cellular factors linked to clinical aggressiveness in cancer. One such factor, Snail, a master regulator of the epithelial-mesenchymal transition (EMT), has been implicated in key tumour biological processes such as invasion and metastasis. In this study we set out to investigate regulation of EMT in hypoxia, and the importance of Snail in cell migration and clinical outcome in breast cancer.

METHODS: Four breast cancer cell lines were exposed to $0.1 \%$ oxygen and expression of EMT markers was monitored. The migratory ability was analysed following Snail overexpression and silencing. Snail expression was assessed in 500 tumour samples from premenopausal breast cancer patients, randomised to either 2 years of tamoxifen or no adjuvant treatment.

RESULTS: Exposure to $0.1 \%$ oxygen resulted in elevated levels of Snail protein, along with changes in vimentin and E-cadherin expression, and in addition increased migration of MDA-MB-468 cells. Overexpression of Snail increased the motility of MCF-7, T-47D and MDA-MB-23I cells, whereas silencing of the protein resulted in decreased migratory propensity of MCF-7, MDA-MB-468 and MDA-MB-23I cells. Moreover, nuclear Snail expression was associated with tumours of higher grade and proliferation rate, but not with disease recurrence. Interestingly, Snail negativity was associated with impaired tamoxifen response $(P=0.048)$.

CONCLUSIONS: Our results demonstrate that hypoxia induces Snail expression but generally not a migratory phenotype, suggesting that hypoxic cells are only partially pushed towards EMT. Furthermore, our study supports the link between Snail and clinically relevant features and treatment response.

British Journal of Cancer (2009) I01, 1769- 1781. doi:I0.1038/sj.bjc.6605369 www.bjcancer.com

Published online 20 October 2009

(C) 2009 Cancer Research UK

Keywords: hypoxia; EMT; Snail; breast cancer; tamoxifen

Epithelial-mesenchymal transition (EMT) is a biological process defining progression from a polarised epithelial phenotype to a mesenchymal phenotype, which is distinguished by fibroblast-like features (Thiery and Sleeman, 2006). Epithelial-mesenchymal transition is characterised by a change in the cell-type-specific protein repertoire and facilitation of cell motility, is essential for generation of new tissue types during embryogenesis, and has a pivotal role in inflammation and wound healing of adult tissue (Thiery, 2003; Flint et al, 2008). In addition, it has been implicated in the fundamental steps of tumorigenesis such as invasion and metastasis (Sleeman, 2000). Epithelial-mesenchymal transition is considered a transient and reversible process and represents only one of several steps required for tumour progression via invasion and metastatic spread (Christiansen and Rajasekaran, 2006). As reviewed by Christiansen et al there are several reports describing

\footnotetext{
*Correspondence: Professor G Landberg, Breakthrough Breast Cancer Research Unit, School of Cancer, Enabling Sciences and Technology, The University of Manchester, Manchester Academic Health Science Centre, The Christie NHS Foundation Trust, Wilmslow Road, Manchester M20 4BX, UK; E-mail: goran.landberg@med.lu.se or glandberg@picr.man.ac.uk Received 26 May 2009; revised 8 September 2009; accepted 17 September 2009; published online 20 October 2009
}

a partial or incomplete EMT phenotype of advanced carcinomas, displaying some mesenchymal features, but with a retention of well-differentiated epithelial-cell characteristics (Christiansen and Rajasekaran, 2006).

The architectural arrangement of an epithelial tissue is characterised by an intricate network of junctional structures such as tight, gap and adherens junctions and desmosomes. Cadherins are important for stabilisation of these structures, and in particular E-cadherin (Matter and Balda, 2003). An important hallmark of EMT is loss of E-cadherin expression, resulting in destabilisation of the cell-cell contacts and detachment of cells from its surroundings. This crucial event results from repression of the E-cadherin gene transcription via overexpression of several different EMT-inducing repressors, such as the zinc-finger transcription factors Slug (Hajra et al, 2002) and the focus of our study; Snail (Barrallo-Gimeno and Nieto, 2005).

Overexpression of Snail has been reported to be a sufficient inducer of EMT as well as being predictor for an aggressive tumour phenotype (Cano et al, 2000). In breast cancer increased Snail expression has been associated with lymph node involvement, invasiveness and metastatic potential (Cheng et al, 2001; Blanco et al, 2002), and also with decreased recurrence-free survival (Moody et al, 2005). Kurrey et al (2005) reported ectopic Snail or Slug expression to result in induction of EMT in an ovarian 
carcinoma cell line, with enhanced motility and invasiveness, loss of expression of epithelial markers and increased expression of vimentin. Stable silencing of endogenous Snail concomitantly induced complete mesenchymal-epithelial transition in MDCKSnail cells, and reduction of in vivo tumour growth of two independent, stably Snail-silenced carcinoma cell lines (Olmeda et al, 2007).

Besides the importance of the tumour cell itself, it is well established that the tumour microenvironment also plays a crucial role in carcinogenesis (Liotta and Kohn, 2001). Hypoxia is a common feature of solid tumours and affects several important biological processes, and is also linked to clinical aggressiveness (Harris, 2002). Hypoxia is predominantly caused by abnormal vasculature formation of the rapidly growing tumour mass, and the net result is heterogeneously distributed areas of low oxygen pressure (Vaupel et al, 2002). Tumour cell adaptation allows survival and gives rise to heterogeneity and selection of resistant clones, consequently resulting in a more malignant phenotype (Semenza, 2003). The hypoxic response mediated by the transcription factor hypoxia-inducible factor-1 (HIF-1) activates target genes involved in a number of different cellular processes, such as proliferation, angiogenesis and EMT, all linked to malignant progression (Semenza, 2002; Imai et al, 2003; Yang and $\mathrm{Wu}, 2008$ ). Upregulation of Snail mRNA expression under hypoxic conditions, accompanied by downregulation of Ecadherin, has been reported in ovarian cancer cell lines (Imai et al, 2003; Kurrey et al, 2005), and invasiveness of hypoxic ovarian cancer cell lines has also been shown to increase (Imai et al, 2003). Furthermore, Lester et al (2007) reported that exposure of the human breast cancer cell line MDA-MB-468 to $1 \%$ oxygen resulted in increased vimentin expression, decreased E-cadherin levels and nuclear translocation of the Snail protein. Notably, these cells adopted a mesenchymal-like morphology, increased their migratory capacity and were able to disseminate in vivo.

Becker et al (2007) published a summary of 21 studies, where 10 were conducted using breast carcinomas, describing the expression of Snail with regard to clinicopathological parameters and disease outcome in a large number of samples from several different cancers. This report points out the discrepancy between studies and the use of different Snail antibodies, and emphasises that selection of novel Snail-specific antibodies may facilitate the establishment of a potential clinical importance for this EMT regulator.

In this study we, thus, focused on elucidating the regulation of EMT via Snail induction, and on the relationship between EMT and hypoxia, in a panel of breast cancer cell lines, using a well validated Snail-specific antibody. Furthermore, the importance of Snail expression in primary breast cancer was examined in a clinical material consisting of 500 invasive premenopausal breast cancer cases, and in full sections of ductal carcinoma in situ (DCIS). We show that Snail protein expression increased in breast cancer cell lines exposed to severe hypoxia $(0.1 \%)$ and that expression of E-cadherin and the mesenchymal marker vimentin were also affected in some cell lines. Nuclear localisation of the protein further seemed to be linked to the EMT-inducing function of Snail. Cell motility increased in one cell line only, following exposure to hypoxia, which turned out to be independent of Snail. Moreover, we demonstrate that Snail expression is important for migration of breast cancer cell lines, through overexpression and silencing of the protein. Finally, nuclear expression of Snail was shown to be associated with higher grade and high proliferation rate in primary breast cancer. In addition, we for the first time show that Snail is a predictor for tamoxifen response.

\section{MATERIALS AND METHODS}

\section{Cell lines, Western blot and immunocytochemistry}

For this study we used the human breast cancer cell lines MCF-7, T47D, MDA-MB-468 and MDA-MB-231 (ATCC, Manassas, VA, USA).
MCF-7 cells were grown in Improved MEM zinc option supplemented with $5 \%$ fetal bovine serum (FBS) and $1 \%$ penicillin/ streptomycin (PEST), T-47D in DMEM supplemented with 10\% FBS and $1 \%$ PEST and MDA-MB-468 and MDA-MB-231 in RPMI 1640 supplemented with $10 \%$ FBS, $1 \mathrm{~mm}$ sodium pyruvate and $1 \%$ PEST. Cell lysates and pellets were made from the cell lines exposed to $0.1 \% \mathrm{O}_{2}$ for increasing time points from 2 to $96 \mathrm{~h}$, where time point zero defined normoxia $\left(21 \% \mathrm{O}_{2}\right)$. Cells were seeded to avoid confluence at the time for harvest. For immunocytochemistry (ICC) cells were harvested by trypsinisation, washed in PBS, fixed in $4 \%$ paraformaldehyde for $25 \mathrm{~min}$, stained with Meyer's haematoxylin for $5 \mathrm{~min}$ and centrifuged at 1500 r.p.m. for $5 \mathrm{~min}$ with the subsequent pellet resuspended in ice-cold $70 \%$ ethanol. Pellets were dehydrated in graded ethanol series, embedded in paraffin and a cell-line array was constructed and stained with antibodies, according to staining procedures described below. For the ICC staining of HIF- $1 \alpha$ the number of HIF- $1 \alpha$-positive cells was counted in three equal fields for each time point and cell line, with an average calculated for each time point.

For Western blot analysis cells were trypsinised, centrifuged, washed and pellets were stored at $-80^{\circ} \mathrm{C}$ for $1 \mathrm{~h}$. Cells were then lysed in buffer containing $0.5 \%$ NP-40, $0.5 \%$ NaDOC, $0.1 \%$ SDS, $50 \mathrm{~mm}$ TRIS (pH 7.0), $150 \mathrm{~mm} \mathrm{NaCl}, 1 \mathrm{~mm}$ EDTA (pH 8.0), $1 \mathrm{~mm}$ $\mathrm{NaF}, 0.1 \mathrm{mg} / \mathrm{ml}$ PMSF and a Complete Mini protease inhibitor cocktail tablet (Roche, Mannheim, Germany). Cell extracts were incubated on ice for $30 \mathrm{~min}$, with vortexing every $10 \mathrm{~min}$, and centrifuged at 14000 r.p.m for $30 \mathrm{~min}$. Supernatants were collected and protein concentrations were measured with a BCA Protein Assay kit (Pierce, Rockford, IL, USA). For each protein sample $10 \mu \mathrm{g}$ was resolved on SDS - polyacrylamide gels and then transferred to Hybond ECL nitrocellulose membranes (Amersham Pharmacia Biotech, Buckinghamshire, UK). Membranes were incubated with rat monoclonal anti-human Snail (1:400, clone SN9H2; Cell Signaling Technology, Beverly, MA, USA), mouse monoclonal anti-human E-cadherin (1:500, clone 4A2C7; Zymed Laboratories, Invitrogen immunodetection, San Francisco, CA, USA), mouse monoclonal anti-human vimentin (1:250, clone V9; Dako, Glostrup, Denmark) antibody and polyclonal goat anti-human $\beta$-actin antibody (1:500; Santa Cruz Biotechnology, Santa Cruz, CA, USA) for $2 \mathrm{~h}$ followed by incubation with secondary horseradish peroxidaseconjugated anti-rat or mouse (Amersham Life Science, Alesbury, UK) and anti-goat antibodies (Sigma, Gothenburg, Sweden) for $1 \mathrm{~h}$. Membrane-bound antibody was detected by using the $\mathrm{ECL}^{+}$system (Amersham Life Science, Alesbury, UK).

\section{Transfections}

For transient expression of wild-type Snail we used the HA-Snail246A plasmid (Yang et al, 2005) provided by Dr Kumar (MD Andersen Cancer Center, Houston). For transfections of MCF-7 and T-47D in six-well plates the Amaxa Nucleofector kit V was used according to the manufacturer's protocol (Amaxa Inc., Gaithersburg, MD, USA). A $2-\mu \mathrm{g}$ weight of DNA was added per well of a six-well plate. MDA-MB-468 and MDA-MB-231 were transiently transfected with Snail vector using Lipofectamine 2000 according to the manufacturer's recommendations (Invitrogen Life Technologies, Carlsbad, CA, USA). A 2- $\mu$ g weight of DNA was used per well of a six-well plate. For Snail knockdown MDA-MB-468 and MDA-MB-231 cells were transfected with $50 \mathrm{nM}$ control siRNA or siRNA against Snail (ON-TARGET plus siRNA SMARTpool; Dharmacon, Lafayette, CO, USA) using Dharmafect (Dharmacon, Lafayette, CO, USA). Cells were allowed to grow 24 or $48 \mathrm{~h}$ after transfection before harvesting for migration assay.

\section{Migration assay}

Migration assays were performed using Transwell migration chambers with $8 \mu \mathrm{m}$ pore membranes (Corning Inc., Corning, 
NY, USA). Cells $\left(10^{5}\right)$ were resuspended in upper Transwell chambers in serum-free media and allowed to migrate towards a serum gradient $(10 \%)$ in the lower chamber for $3 \mathrm{~h}$ (MDA-MB-231) or $6 \mathrm{~h}$ (MCF-7, T-47D and MDA-MB-468). Membranes were then excised and cells on the upper side were removed before fixing in $4 \%$ paraformaldehyde and staining with DAPI (4'6-diamidino-2phenylindole), prior to mounting. The number of migrating cells was counted in three randomly chosen fields on each membrane and photographed at $\times 10$ magnification. Values reported are the averages of three experiments performed in triplicates.

\section{Patient material}

Patient cohort Between 1986 and 1991, 564 premenopausal breast cancer patients with invasive stage-II disease were enrolled in a Swedish trial (SBII:2a) where they were randomly assigned to 2 years of adjuvant tamoxifen $(n=276)$ or no adjuvant treatment (control, $n=288$ ). The aim of the original study was examine the effect of tamoxifen treatment (20 or $40 \mathrm{mg}$ daily) on recurrencefree survival. Patients were included irrespective of hormone receptor status. All patients were followed up for recurrence-free and overall survival. Recurrence was defined as local, regional or distant recurrence, and breast cancer-specific death. A new contralateral breast cancer was not recorded as recurrence, but was separately analysed. Surgery was modified radical mastectomy or breast conserving surgery, followed by radiotherapy, and in few cases adjuvant polychemotherapy (less than $2 \%$ ). The median post-surgery follow-up time without breast cancer event was 13.9 years. Detailed description of the SBII:2a study can be further obtained from a previous report (Ryden et al, 2005). Informed consent was obtained from the patients participating in the randomised study and the ethical committees at Lund and Linköping Universities approved the study and the reanalysis of the tumour material.

\section{Ductal carcinoma in situ}

Twenty-five full sections taken from patients with DCIS were chosen from archived formalin-fixed, paraffin-embedded surgical breast tumour specimens at Department of Pathology, Malmö University Hospital. Inclusion criteria were symmetrical DCIS lesions with central necrosis.

\section{Tissue specimens and immunohistochemistry}

Formalin-fixed, paraffin-embedded tumour material was available from 500 of the 564 patients in the trial. Areas representative of invasive cancer were selected and assembled in a tissue microarray (TMA). Two 0.6-mm tissue cores from each donor block were placed in recipient paraffin blocks using an automated tissue arrayer (Beecher Instruments Microarray Technology, Woodland, MD, USA). Sections ( $4 \mu \mathrm{m})$ from this block were mounted on slides before they were deparaffinised, rehydrated and microwavetreated in target retrieval solution at $\mathrm{pH} 9.9$ (Dako, Glostrup, Denmark), before being processed with an automated immunostainer (Techmate 500; Dako, Copenhagen, Denmark), using the Envision software (Dako, Glostrup, Denmark). The antibody employed was Snail (1:100). Staining was evaluated by two independent observers (one pathologist), to obtain a result as correct and representative as possible. Conflicting observations were low $(<5 \%)$ for all evaluations made. All immunohistochemical (IHC) evaluations were performed without knowledge of tumour characteristics. In cases of no evaluation, cores were either non-representative (i.e., contained no invasive tumour cells) or missing. Data for expression of the oestrogen receptor- $\alpha(\mathrm{ER} \alpha)$ and the progesterone receptor (PR) were available from a previous study (Ryden et al, 2005). Expression of the proliferation marker Ki67 had also been evaluated in a previous study (Jirstrom et al,
2005). Carbonic anhydrase-IX (CAIX) staining (Brennan et al, 2006) as well as HIF- $1 \alpha$ staining (Kronblad et al, 2006) had also previously been evaluated. Formalin-fixed, paraffin-embedded full section DCIS and arrays of cell pellets were treated as previously described. Antibodies employed were Snail (1:100), E-cadherin (1:100), vimentin (1:1000) and mouse monoclonal anti-human HIF-1 $\alpha$ (1:100, clone 54; BD Biosciences, Erembodegem, Belgium).

\section{ICC evaluation of cytoplasmic and nuclear Snail expression}

SlidePath's Positive Pixels Algorithm (Digital Slide Server) was used for evaluation of ICC staining of cytoplasmic Snail protein in the different cell lines. The algorithm detects positively stained pixels within the image. The analysis was performed on three randomly chosen fields for each time point and cell line, on the array made from cell pellets, and an average was calculated. For more detailed description we refer to the Tissue Image Analysis User Guide (SlidePath Ltd., Dublin, Ireland). For the ICC staining of nuclear Snail the percentage positive nuclei was manually counted in three equal fields for each time point and cell line, with an average calculated for each time point.

\section{Statistical methods}

Statistical analyses were performed using the SPSS software (version 15.0; SPSS, Chicago, IL, USA). The Wilcoxon/MannWhitney test and Fisher's exact test were used for associations between Snail expression and clinicopathological parameters and tumour markers. To study recurrence-free survival the KaplanMeier method was used, and the log-rank test was applied for comparison of recurrence-free survival among different treatment groups. A Cox proportional-hazards regression model was used for the estimation of relative risk in multivariate analysis. All $P$-values corresponded to two-sided tests and a $P$-value less than 0.05 was considered statistically significant.

\section{RESULTS}

\section{Snail is expressed in breast cancer cell lines}

Prior to this study we had been evaluating a number of different Snail antibodies and found that some were unspecific and reacted also with the closely related family member Slug. The reactivity of the Snail-specific antibody used in our study was further validated through comparison of the expression pattern by Western blot and immunocytochemical analysis of protein lysates and pellets made from the human breast cancer cell lines MCF-7, T-47D, MDA-MB468 and MDA-MB-231. Both methods revealed a similar expression pattern for the protein in the cell lines (data not shown). Staining was both nuclear and cytoplasmic, as observed by ICC. In Western blot a band corresponding to the predicted molecular weight for Snail was obtained at $29 \mathrm{kDa}$ (Supplementary Figure 1). Bands corresponding to the EMT markers E-cadherin and vimentin were obtained at $\sim 100$ and $54 \mathrm{kDa}$, respectively (Supplementary Figure 1).

\section{Hypoxia induces an EMT phenotype in breast cancer cell lines}

First, the effect of hypoxia on EMT regulation was studied in the four cell lines. Cells were exposed to $0.1 \%$ oxygen from 2 to $96 \mathrm{~h}$. Expression of HIF- $1 \alpha$ was used to visualise the hypoxic response, and the expression pattern differed between the four cell lines. Expression of HIF- $1 \alpha$ peaked between 4 and $8 \mathrm{~h}$ in all cell lines, and then declined (Figure 1A). For MCF-7, and MDA-MB-231 a less prominent expression peak was observed at 48 and $24 \mathrm{~h}$ respectively. Interestingly, exposure to $0.1 \%$ oxygen increased 

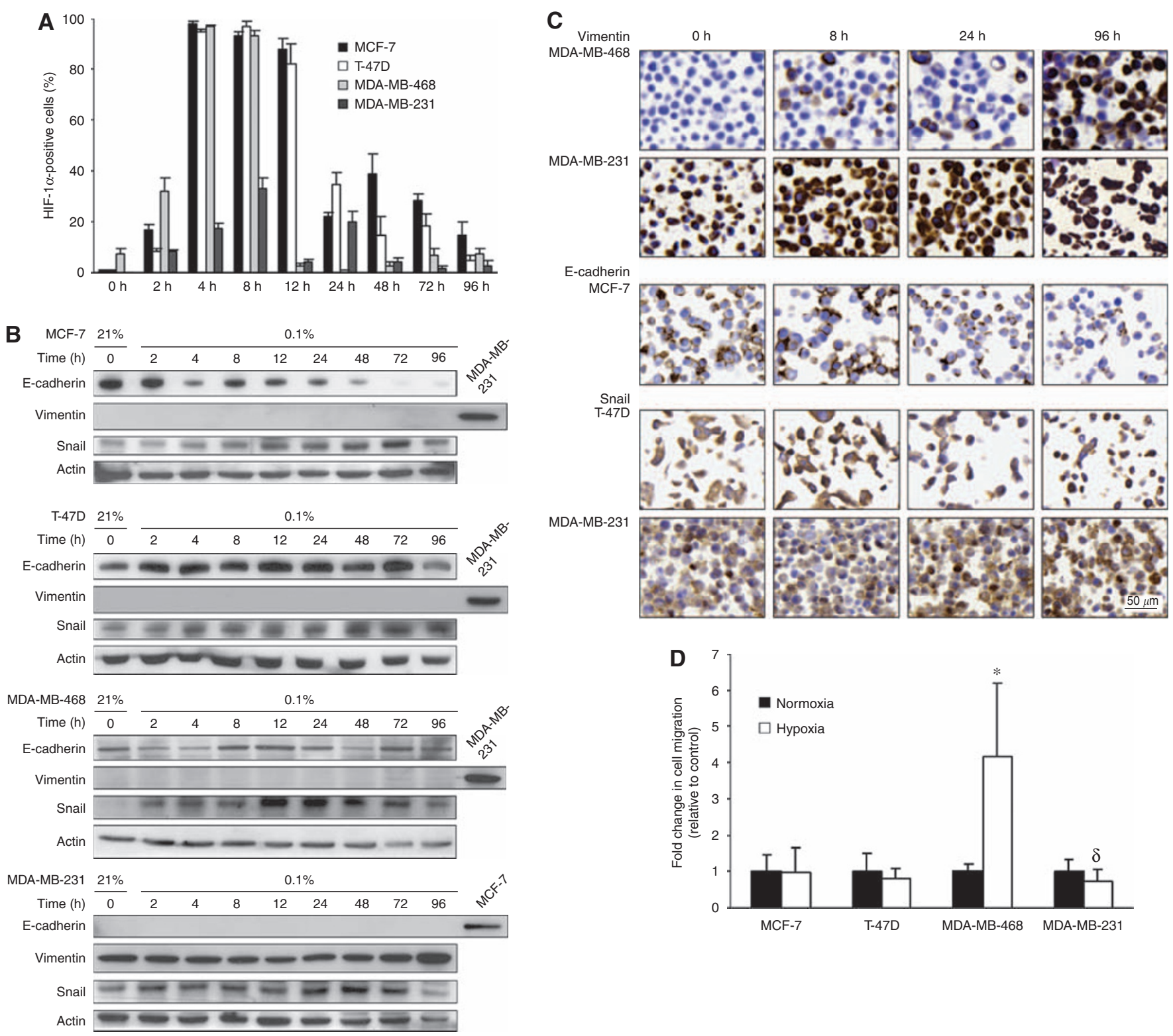

Figure I EMT marker expression and migratory capacity in breast cancer cell lines exposed to hypoxia. (A) HIF- I $\alpha$ expression representing the hypoxic response peaked between 4 and $8 \mathrm{~h}$ in all cell lines, and again at $48 \mathrm{~h}$ but with a lower expression level in MCF-7 cells, and at 24 h in MDA-MB-23I cells. (B) Snail expression increased in all the cell lines, with a slight variation in expression levels over time. E-cadherin protein levels decreased in MCF-7 cells starting at $4 \mathrm{~h}$ and was significantly reduced after $72 \mathrm{~h}$, and fluctuated over time in MDA-MB-468 cells. A slight increase of vimentin expression was detected in Western blot in MDA-MB-468 and MDA-MB-23I cells. (C) Vimentin expression detected by ICC increased in MDA-MB-468 and MDA-MB-23I cells upon hypoxic exposure, and was markedly upregulated at $96 \mathrm{~h}$ in both cell lines. The ICC confirms downregulation of E-cadherin in MCF-7 cells and increased levels of both cytoplasmic and nuclear Snail is exemplified for T-47D and MDA-MB-23I cells. (D) The migratory ability of MDA-MB-468 cells increased three-fold $(* P<0.00 \mathrm{I})$ vs control when cells were exposed to $0.1 \%$ oxygen for $48 \mathrm{~h}$, whereas significantly decreased in hypoxic MDA-MB-23I cells $\left({ }^{\delta} P<0.00 \mathrm{I}\right)$ vs control. The result in panel $\mathbf{D}$ is presented as means of three experiments.

the protein levels of Snail in all cell lines. Snail expression increased over time, but with a slightly different expression pattern among cell lines, as demonstrated by Western blot (Figure 1B). Similar observations were made on ICC stainings of cell pellets, as shown for T-47D and MDA-MB-231 (Figure 1C). Cytoplasmic intensity as well as number of cells exhibiting nuclear Snail expression increased over time. E-cadherin protein expression, which was present in all cell lines except for MDA-MB231, decreased only in MCF-7 cells, starting at approximately $4 \mathrm{~h}$, and after $72 \mathrm{~h}$ the expression was significantly reduced (Figure $1 \mathrm{~B}$ and $\mathrm{C})$. Expression of the mesenchymal marker vimentin, which is expressed only by MDA-MB-231 cells at normoxia, increased during exposure of MDA-MB-468 and MDA-MB-231 to hypoxia, more easily detectable by ICC (Figure 1B and C). Proliferation, as measured by Ki67, was maintained at a high level throughout the time course of hypoxic exposure (Supplementary Figure 2). Since EMT is associated with tumour invasiveness and metastasis, we wanted to confirm that EMT-induced cells are motile. Interestingly, we found that the migratory capacity of MDA-MB-468 cells exposed to hypoxia for $48 \mathrm{~h}$ increased three-fold relative to normoxic cells (Figure 1D). However, migration was not affected in MCF-7 and T-47D cells, and in contrast, MDA-MB-231 cells exhibited significantly lower migratory ability when exposed to hypoxia (Figure 1D). Taken together, 
exposure of these breast cancer cell lines to hypoxia induced partial EMT that affected the migratory ability in one of the four cell lines (Table 1).

Table I Expression of EMT markers and migratory potential of breast cancer cell lines exposed to $0.1 \%$ oxygen

\begin{tabular}{lcccc}
\hline & E-cadherin & Snail & Vimentin & Migration \\
\hline MCF-7 & $\boldsymbol{\nabla}$ & $\mathbf{\Delta}$ & - & $\mathbf{0}$ \\
T-47D & $\mathbf{\square}$ & $\mathbf{\Delta}$ & $\overline{\mathbf{0}}$ & $\mathbf{\Delta}$ \\
MDA-MB-468 & $\mathbf{E}$ & $\mathbf{\Delta}$ & $\mathbf{\Delta}$ & $\mathbf{\nabla}$ \\
MDA-MB-231 & - & $\mathbf{\Delta}$ &
\end{tabular}

Abbreviations: EMT = epithelial-mesenchymal transition. - , no expression; $\mathbf{\square}$, no change; $\mathbf{\nabla}$, downregulation; $\boldsymbol{\Lambda}$, upregulation.
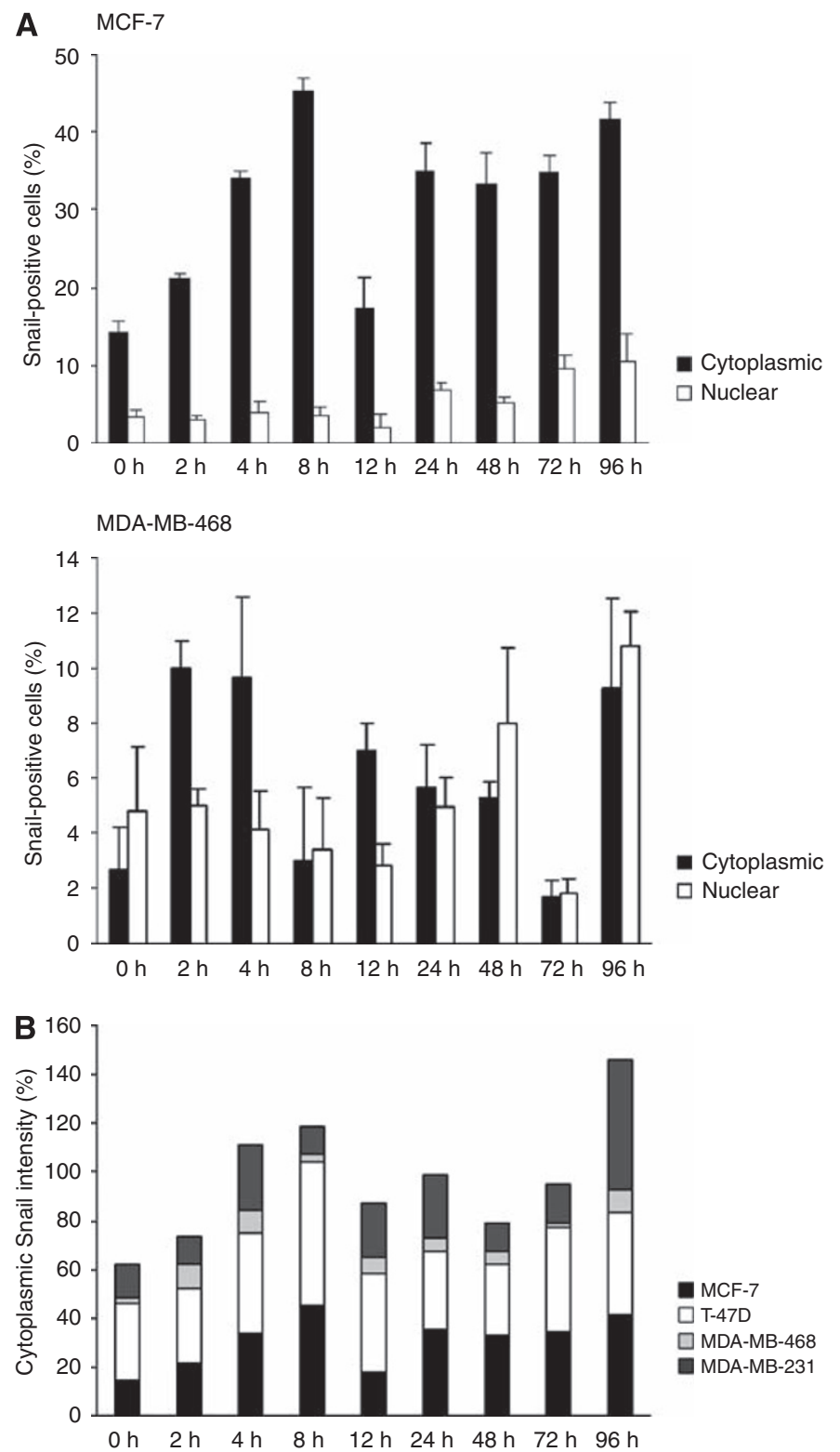

\section{Subcellular localisation of Snail is affected by hypoxia}

Our next objective was to analyse the subcellular localisation of Snail as an effect of hypoxic exposure. Cytoplasmic staining intensity, measured by the Positive Pixels Algorithm (developed by SlidePath Ltd., Dublin, Ireland), increased over time. In all four cell lines the expression levels peaked between 2 and $8 \mathrm{~h}$, and then again between 72 and $96 \mathrm{~h}$ (Figure 2A). The lowest expression of cytoplasmic Snail was observed in MDA-MB-468 cells. In contrast to the cytoplasmic expression, nuclear expression started to increase later during hypoxic exposure and peaked at $96 \mathrm{~h}$ in all cell lines except for in T-47D. Nuclear expression in T-47D was retained at a quite low level throughout the time course of exposure (Figure 2A). Interestingly, the elevated levels of nuclear Snail detected at later time points corresponded to those in time

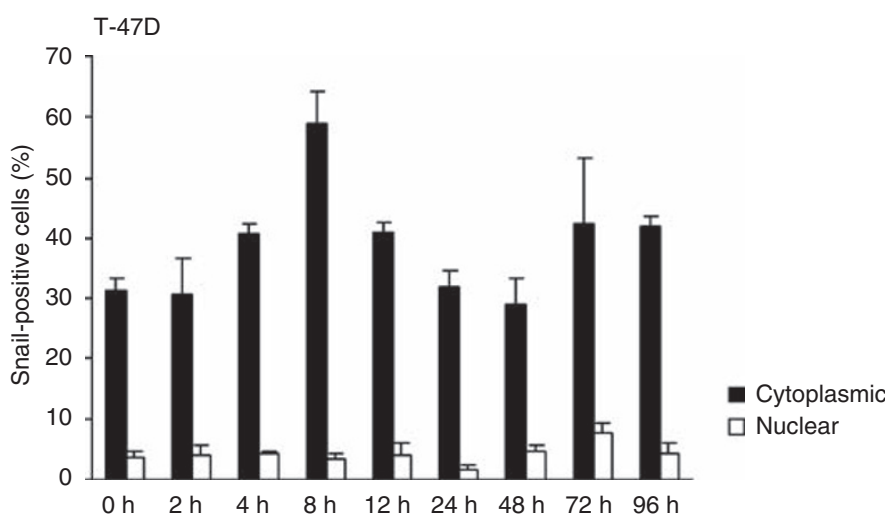

MDA-MB-231
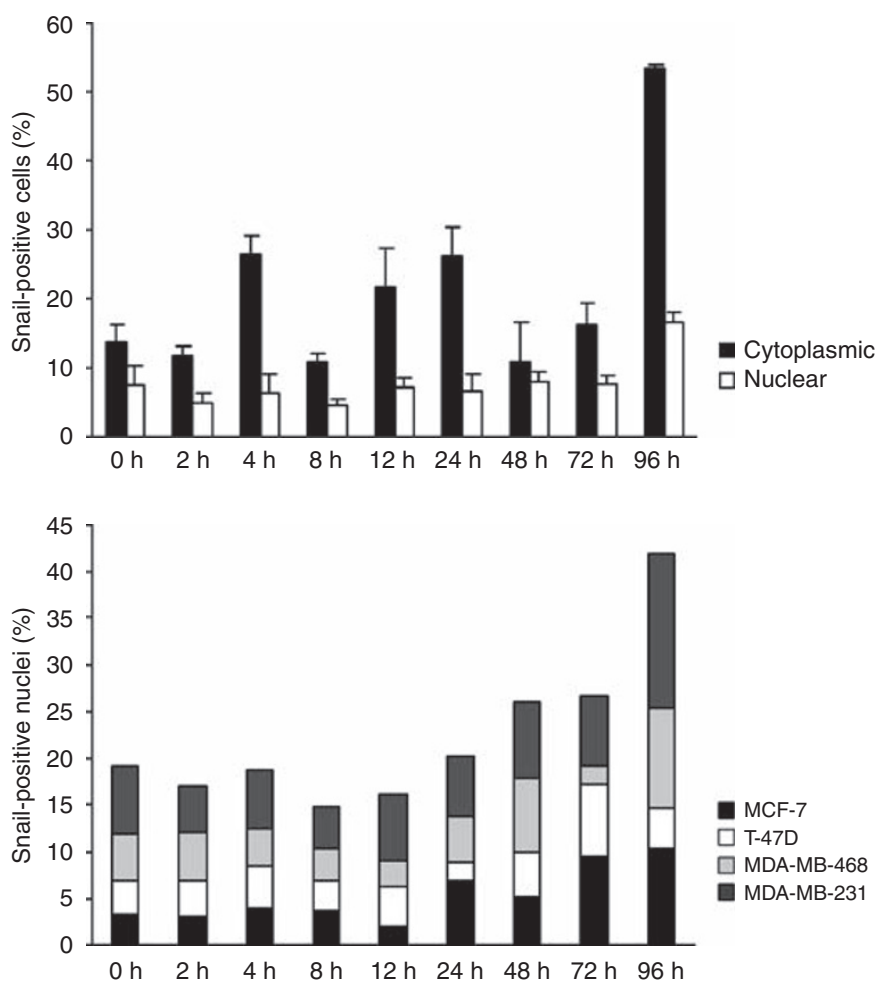

Figure 2 Subcellular localisation of Snail in breast cancer cells exposed to hypoxia. (A) In MCF-7 cells hypoxia induced cytoplasmic Snail expression with a peak at $8 \mathrm{~h}$, followed by a decline at $12 \mathrm{~h}$ and again an increased expression. Nuclear expression was increasing over time and peaked at $96 \mathrm{~h}$. Expression of Snail in T-47D fluctuated over time, with a cytoplasmic expression peak at $8 \mathrm{~h}$, but no prominent expression peak in the nuclear expression was observed. Cytoplasmic Snail expression fluctuated over time in MDA-MB-468, with somewhat lower levels between 8 and $72 \mathrm{~h}$, whereas nuclear expression peaked at 96 h. In MDA-MB-23I cells cytoplasmic as well as nuclear expression showed a prominent peak at $96 \mathrm{~h}$. (B) When adding expression levels of all cell lines, two different expression peaks were observed for cytoplasmic expression, the first one at $8 \mathrm{~h}$ and the second at $96 \mathrm{~h}$. Nuclear Snail expression reached its highest levels at $96 \mathrm{~h}$, when presented for all the cell lines. 
points when prominent changes in E-cadherin in MCF-7 cells, and vimentin expression in MDA-MB-468 and MDA-231 were observed. Adding the expression levels of all the cell lines, two expression peaks for cytoplasmic expression were observed, one at $8 \mathrm{~h}$ and the second at $96 \mathrm{~h}$ (Figure 2B). Since nuclear expression peaked at $96 \mathrm{~h}$ in all cell lines except for T-47D, one prominent peak was detected at $96 \mathrm{~h}$ when adding the expression of all the cell lines (Figure 2B).

A
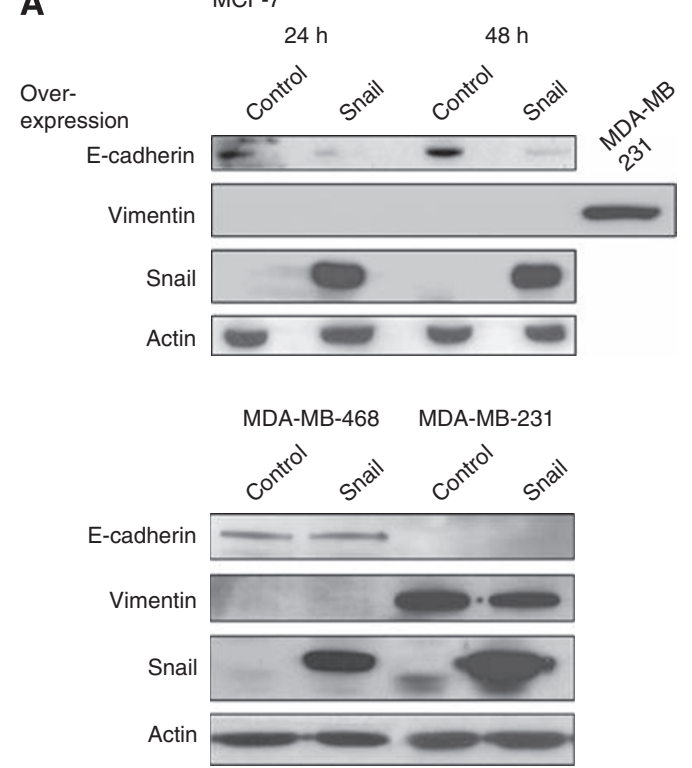

\section{Overexpression and silencing of Snail impacts upon breast cancer cell migration}

In order to further investigate the role of Snail in cell motility, we transiently overexpressed and silenced the protein in the cell lines (Figure 3A). With the exception of MDA-MB-468 cells, the moderate increase in Snail expression following hypoxic exposure did not increase the migratory capacity of the cell lines. Hence, we
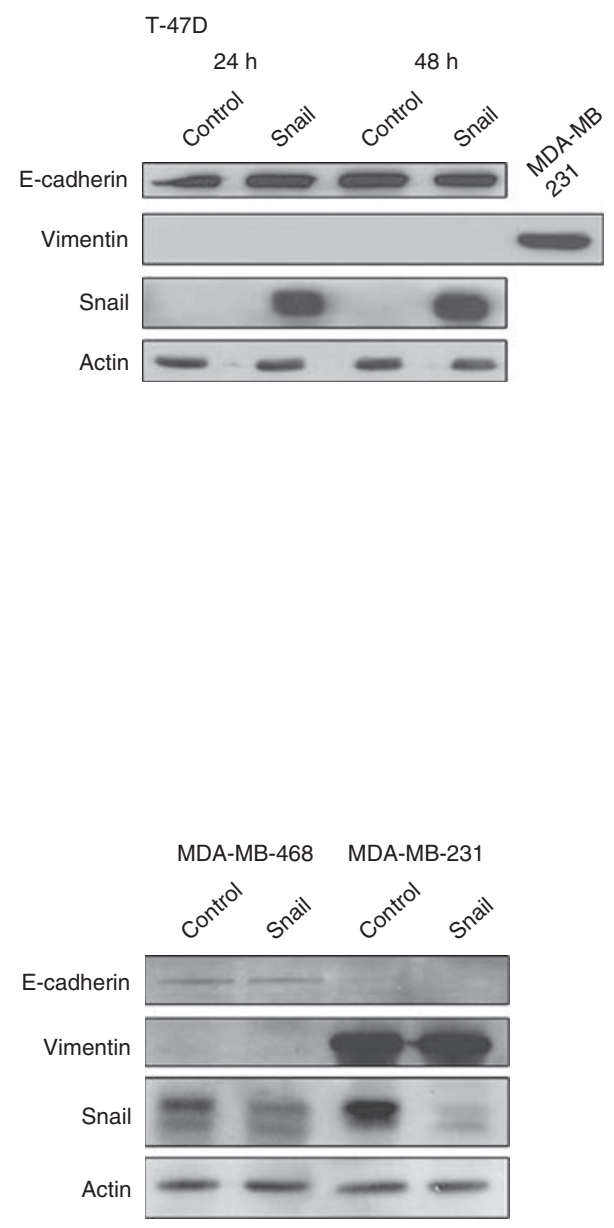

Figure 3 Effect of transient overexpression and silencing of Snail on the migratory ability of breast cancer cell lines. (A) Western blots confirming overexpression and knockdown of Snail and expression of E-cadherin and vimentin for the four cell lines. In MCF-7 cells transfected with Snail vector a decrease in E-cadherin protein levels was observed, and a slight increase in E-cadherin expression could be detected when Snail was silenced. Absence of bands in the control lanes for overexpression was due to short exposure times. In MDA-MB-468 cells exposed to hypoxia, vimentin expression decreased following Snail knockdown. (B) Snail overexpression increased migration of MCF-7 and T-47D cells 24h (*, MCF-7: $P=0.034 ;$ T-47D: $P=0.025)$ and 48 h $(\delta$, MCF-7: $P=0.002$; T-47D: $P=0.043$ ) post transfection. $(\mathbf{C})$ The migratory ability of Snail-overexpressing cells increased also in MDA-MB-23। cells (* $P<0.00 \mathrm{I}$ ) vs control $48 \mathrm{~h}$ post transfection, whereas no change was observed in MDA-MB-468 cells. (D) Knockdown of Snail resulted in decreased migration of MCF-7 cells $(* P<0.00$ I $)$ vs control, but no effect was observed in T-47D cells $(\mathbf{E})$ Snail silencing in MDA-MB-468 and MDA-MB-23I decreased the migratory ability vs control $48 \mathrm{~h}$ post transfection $\left(* P<0.00 \mathrm{I},{ }^{\delta} \mathrm{P}<0.00 \mathrm{I}\right.$ ). (F) Snail knockdown in MDA-MB-468 cells exposed to hypoxia did not exhibit the decreased migratory propensity observed for normoxic cells treated with siRNA against Snail. There was a significant difference in migration between normoxic and hypoxic cells $(* P=0.028)$, and between normoxic control-transfected and Snail-transfected cells $\left({ }^{\delta} P=0.023\right)$. The results are presented as means of three experiments. Wide error bars for MCF-7 and T-47D cell migrations are due to low and varying cell number between experiments. 

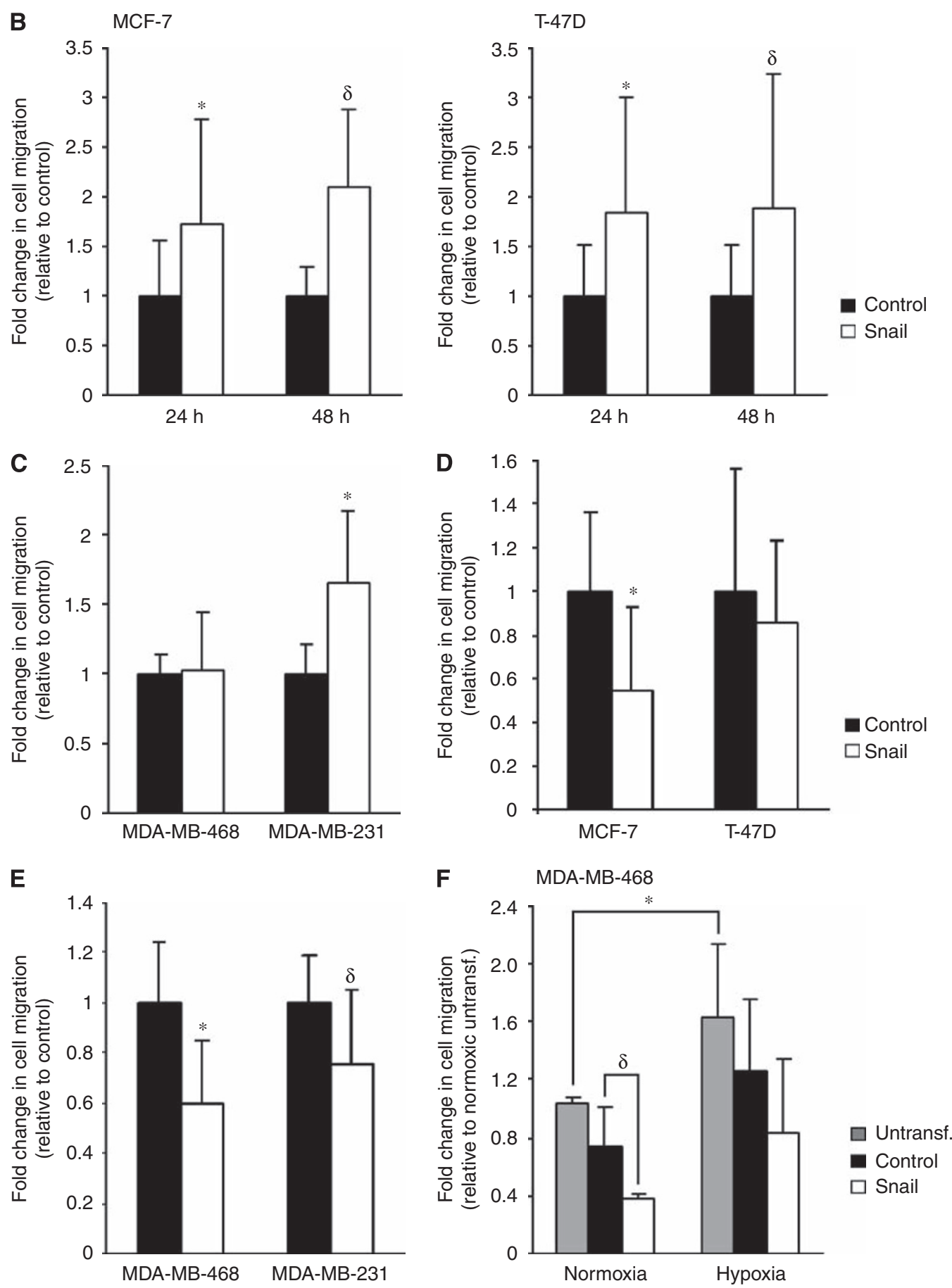

Figure 3 Continued.

wanted to elucidate the effect of a prominent increase in Snail expression on migration. The migratory capacity of the epitheliallike cell lines MCF-7 and T-47D is low, MDA-MB-468 moderate, and the mesenchymal-like MDA-MB-231 is highly migratory (Supplementary Figure 3). Overexpression of Snail in MCF-7 and T-47D cells resulted in significant increase in cell motility, 24 and $48 \mathrm{~h}$ post transfection, relative to the control (Figure $3 \mathrm{~B}$ ). Notably, migration of T-47D was effected even though E-cadherin was not downregulated as a result of elevated Snail levels (Figure 3A). Furthermore, Snail overexpression resulted in increased migration of MDA-MB-231 cells, whereas no effect on MDA-MB-468 cell migration was observed (Figure 3C). No significant changes in the expression of either E-cadherin or vimentin were found when Snail was overexpressed in these two cell lines (Figure 3A). To exclude the possibility that increased migration following overexpression of Snail was just an artefact of the actual overexpression, we, in addition, overexpressed the closely related E-cadherin repressor Slug in the cell lines. This however, did not result in enhanced migratory capacity in any of the cell lines (data not shown). Moreover, silencing of Snail expression in MCF-7, MDA-MB-468 and MDA-MB-231 decreased cell migration significantly, whereas no effect of the knockdown was observed in T-47D cells (Figure 3D 
and E). Notably, E-cadherin and vimentin levels were unaffected when Snail was knocked down, except for a slightly elevated E-cadherin level in MCF-7 cells (Figure 3A).

We further wanted to delineate the link between hypoxia induced Snail expression and migration in MDA-MB-468 cells, since the migratory capacity of this only cell line increased as a result of exposure to hypoxia. Snail was silenced by siRNA and cells were grown for $48 \mathrm{~h}$ in either normoxia ( $21 \%$ oxygen) or in hypoxia prior to migration. We again observed a significantly decreased migration of normoxic cells transfected with siRNA against Snail, relative to the control (Figure 3F). However, motility of hypoxic cells transfected with siRNA against Snail was in contrast not significantly decreased due to the knockdown, relative to control-transfected hypoxic cells (Figure 3F). These results indicate that the increased migratory ability of MDA-MB-468 cells observed in hypoxia was independent of Snail, and may instead be dependent on another factor, or a number of different factors activated by the hypoxic response.

\section{Nuclear Snail expression is associated with higher grade and proliferation rate, and is a predictive marker for tamoxifen response in premenopausal breast cancer}

Next, we examined potential associations between Snail expression and tumour characteristics. The tumour material collected from a clinical trial of patients randomised to either 2 years of tamoxifen or no adjuvant treatment after surgery allowed us to investigate the prognostic effect of Snail expression. Nuclear staining was assessed as being absent (0) (Figure 4A) or present (1) (Figure 4B). Based on those criteria $293(76.3 \%)$ and $91(23.7 \%)$ tumours out of the 384 that were assessable, displayed absence or presence of nuclear Snail staining respectively (Table 2). The majority of tumours displayed cytoplasmic staining of varying intensity, but we chose to focus on nuclear staining since Snail is active in the nucleus, with its functional role as a transcriptional repressor of the Ecadherin gene. Interestingly, expression of Snail was positively correlated to tumour grade $(P=0.003)$ and to expression of the proliferation marker Ki67 $(P=0.024)$, implying that nuclear Snail expression is associated with markers defining a more aggressive disease in breast cancer (Table 2). However, no associations with clinicopathological parameters such as tumour size, tumour type or lymph node status were found. Moreover, nuclear expression of Snail was inversely correlated to expression of both the ER $\alpha$
$(P=0.002)$ and the PR $(P=0.006)$ (Table 2$)$. No correlation was observed between Snail expression and HIF-1 $\alpha$, but a positive correlation to expression of the hypoxia marker CAIX $(P=0.040)$ was found, suggesting a possible link between EMT and hypoxia in breast cancer (Table 2). Notably, cytoplasmic Snail expression was not associated with any of the variables described. We examined recurrence-free survival among patients in the untreated control group according to Snail expression; however, Snail expression had no prognostic value (Figure 5A). Survival analyses revealed a trend towards impaired tamoxifen response among patients with Snail-negative tumours, compared with the those having Snailpositive tumours (Figure 5B and C). Interestingly, when analysing patients randomised to tamoxifen treatment $v s$ no adjuvant treatment, using a multivariate Cox proportional-hazards regression model for Snail and treatment interaction, a statistically significant difference between the two subgroups defined by nuclear Snail expression was observed $(P=0.048)$ (Table 3$)$. These results indicate that patients with tumours exhibiting no nuclear Snail expression are less likely to respond to tamoxifen, as compared with patients with Snail-positive tumours.

\section{Hypoxic cells of DCIS express nuclear Snail}

We continued by investigating the expression of Snail in a model system of hypoxia in vivo, non-invasive DCIS; DCIS lesions are often presented with areas of central necrosis where hypoxic tumour cells are surrounding the necrotic zone. Our aim was to elucidate whether these hypoxic cells displayed an EMT phenotype. Hypoxia-inducible factor- $1 \alpha$ staining of full sections of DCIS confirmed the presence of hypoxia in cell layers adjacent to the central necrosis. Staining intensity and number of HIF- $1 \alpha$-positive cells however, varied noticeably between samples and lesions, suggesting antibody unreliability. The typical HIF- $1 \alpha$ expression pattern that distinguishes DCIS is shown in Figure 6A (Helczynska et al, 2003). Cytoplasmic Snail expression was present in the majority of cells, whereas nuclear expression gradually increased approaching the necrosis, in a number of DCIS samples (Figure 6B and C). However, E-cadherin and vimentin expression was not changed in close proximity of the central necrosis (data not shown). Hence, DCIS did not display EMT-like features, but the results again confirmed that hypoxia induces Snail expression, and that this induction does not necessarily affect other EMT markers.
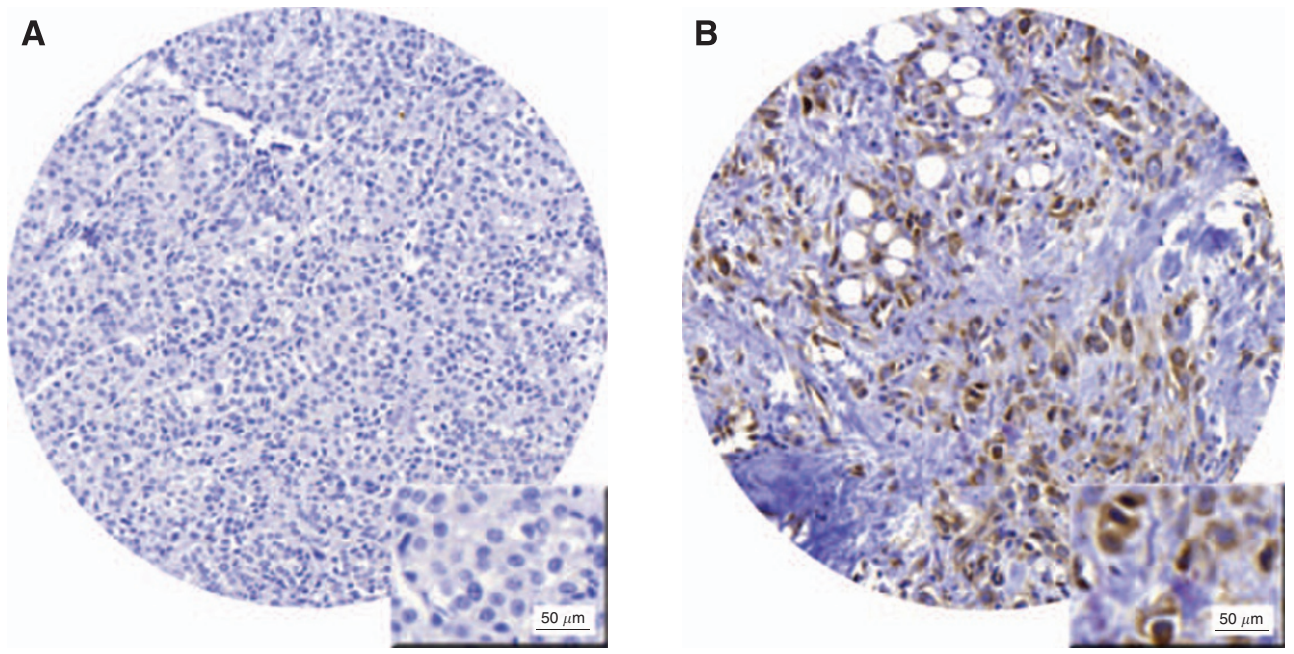

Figure 4 Expression of Snail in primary breast tumours. (A) Tumour core exhibiting absence of Snail expression. (B) A fraction of tumours showed presence of nuclear Snail expression. 
Table 2 Distribution of Snail staining category according to clinicopathological and molecular parameters of invasive breast cancer

\begin{tabular}{|c|c|c|c|}
\hline \multirow[b]{2}{*}{ Variable } & \multicolumn{3}{|c|}{ Snail nuclear staining } \\
\hline & $\begin{array}{l}\text { Negative } \\
(n=293)\end{array}$ & $\begin{array}{l}\text { Positive } \\
(n=91)\end{array}$ & $P^{\mathbf{a}}$ \\
\hline $\begin{array}{l}\text { Tumour size }(\mathrm{mm}) \\
\quad \leqslant 20 \\
>20 \\
\text { Missing cases: } 117\end{array}$ & $\begin{array}{l}106 \\
186\end{array}$ & $\begin{array}{l}34 \\
57\end{array}$ & 0.901 \\
\hline $\begin{array}{l}\text { Tumour type } \\
\text { Ductal } \\
\text { Lobular } \\
\text { Medullary } \\
\text { Missing cases: 131 }\end{array}$ & $\begin{array}{r}246 \\
20 \\
14\end{array}$ & $\begin{array}{r}75 \\
7 \\
7\end{array}$ & $0.361^{b}$ \\
\hline $\begin{array}{l}\text { Lymph node status } \\
\text { Negative } \\
\text { Positive } \\
\text { Missing cases: } 117\end{array}$ & $\begin{array}{r}80 \\
212\end{array}$ & $\begin{array}{l}26 \\
65\end{array}$ & 0.893 \\
\hline $\begin{array}{l}\text { NHG } \\
\quad \mid \\
\| \\
\text { III } \\
\text { Missing cases: } 129\end{array}$ & $\begin{array}{r}35 \\
132 \\
116\end{array}$ & $\begin{array}{r}6 \\
30 \\
52\end{array}$ & $0.003^{b}$ \\
\hline $\begin{array}{l}\text { Ki67 positive (\%) } \\
0-1 \\
2-10 \\
11-25 \\
26-50 \\
51-100 \\
\text { Missing cases: } 155\end{array}$ & $\begin{array}{l}41 \\
84 \\
67 \\
35 \\
31\end{array}$ & $\begin{array}{r}7 \\
24 \\
27 \\
14 \\
15\end{array}$ & $0.024^{b}$ \\
\hline $\begin{array}{l}\text { ER } \alpha \text { positive (\%) } \\
\quad<10 \\
\quad \geqslant 10 \\
\text { Missing cases: } 130\end{array}$ & $\begin{array}{r}76 \\
203\end{array}$ & $\begin{array}{l}41 \\
50\end{array}$ & 0.002 \\
\hline $\begin{array}{l}P R \text { positive (\%) } \\
\quad<10 \\
\geqslant 10 \\
\text { Missing cases: } 139\end{array}$ & $\begin{array}{r}79 \\
194\end{array}$ & $\begin{array}{l}40 \\
48\end{array}$ & 0.006 \\
\hline $\begin{array}{l}H I F-1 \alpha(\%) \\
\quad 0-1 \\
2-10 \\
11-100 \\
\text { Missing cases: } 190\end{array}$ & $\begin{array}{r}176 \\
36 \\
19\end{array}$ & $\begin{array}{r}53 \\
18 \\
8\end{array}$ & $0.129^{b}$ \\
\hline $\begin{array}{l}\text { CAIX } \\
\text { Negative } \\
\text { Positive } \\
\text { Missing cases: } 179\end{array}$ & $\begin{array}{r}219 \\
21\end{array}$ & $\begin{array}{l}67 \\
14\end{array}$ & 0.040 \\
\hline
\end{tabular}

Abbreviations: $\quad C A I X=$ carbonic $\quad$ anhydrase-IX; $\quad E R=$ oestrogen receptor: $\mathrm{HIF}=$ hypoxia-inducible factor; NHG = Nottingham Histologic Grade; PR = progesterone receptor. ${ }^{\text {aCC}}$ Correlations were calculated using Fisher's exact test (two-sided) unless otherwise specified. ' Wilcoxon/Mann-Whitney test (two-sided).

\section{DISCUSSION}

Epithelial-mesenchymal transition is described as a dynamic and reversible biological process. As cells from a solid tumour escape via the circulation and set metastases at new sites due to conversion of epithelial cells into mesenchymal cells, these cells are likely to revert back into epithelial cells at the distant site (Thiery and Sleeman, 2006; Peinado et al, 2007). We have shown in
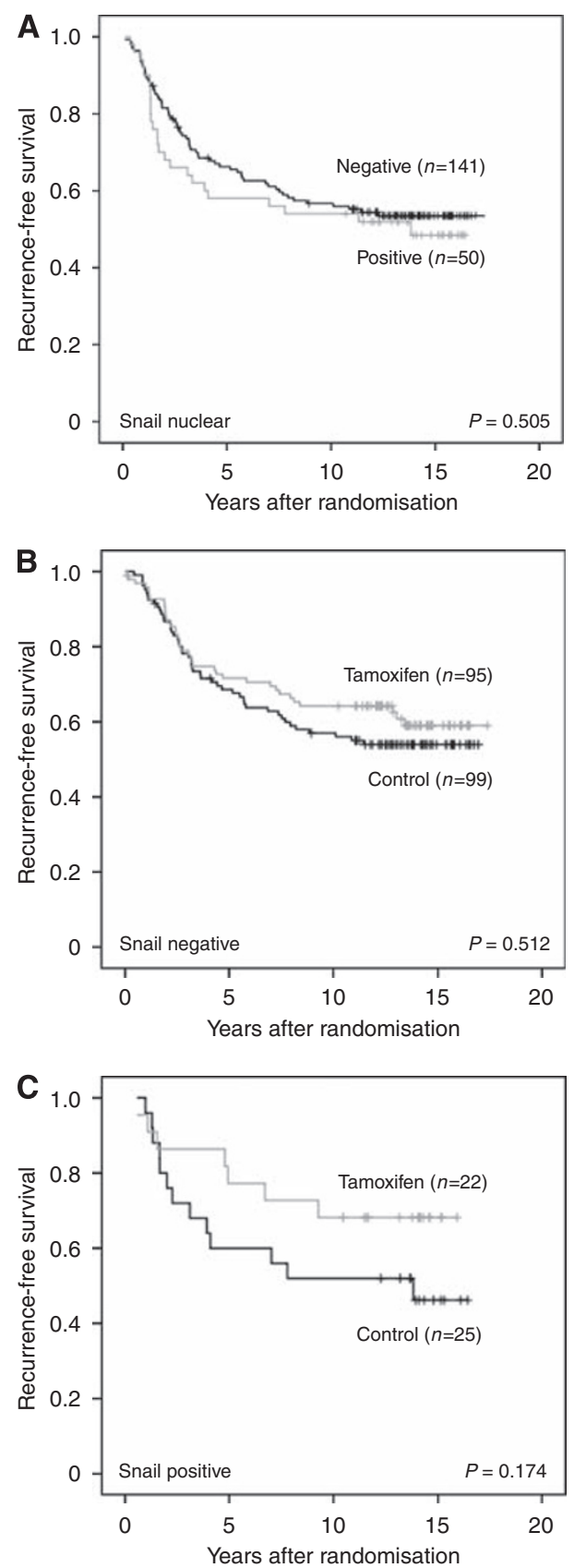

Figure 5 Kaplan-Meier curves showing the effect of Snail on recurrence-free survival. (A) In the subgroup of untreated control patients expression of nuclear Snail had no effect on the recurrence rate. (B) For patients with $E R \alpha$-positive, Snail-negative tumours no difference in recurrence-free survival was observed between untreated and treated patients. (C) A trend towards shorter recurrence-free survival for untreated ER $\alpha$-positive, Snail-positive patients as compared with treated patients, was observed.

this study that breast cancer cells can exhibit partially induced EMT, where Snail induction as a result of hypoxia does not elicit a motile phenotype even though levels of mesenchymal markers such as vimentin are increased and E-cadherin levels decrease. Snail induction resulting from overexpression can conversely result in a migratory phenotype despite retention of vimentin and E-cadherin expression levels. Exposure of these breast cancer cell lines to severe hypoxia induced a shift towards an EMT phenotype, 
with elevated levels of Snail protein in all the cell lines, decreased expression of E-cadherin in MCF-7 cells and increased vimentin expression in MDA-MB-468 and MDA-MB-231 cells. However,

Table 3 Multivariate Cox proportional-hazards model for Snail and treatment interaction based on $E R \alpha$-positive breast cancer patients $(n=325)^{a}$

\begin{tabular}{llccc}
\hline & & \multicolumn{3}{c}{ Recurrence-free survival } \\
\cline { 3 - 5 } Variable & HR & $\mathbf{9 5 \%} \mathbf{C l}$ & $\mathbf{P}$ \\
\hline Snail nuclear & Negative versus positive & $0.252^{\mathrm{b}}$ & $0.054-1.184$ & 0.081 \\
Treatment & Tamoxifen versus control & $0.300^{\mathrm{c}}$ & $0.116-0.776$ & 0.013 \\
Interaction variable & Tamoxifen $\times$ Snail nuclear & 2.911 & $1.009-8.395$ & 0.048 \\
& & &
\end{tabular}

Abbreviations: $\mathrm{Cl}=$ confidence interval; $\mathrm{ER}=$ oestrogen receptor; $\mathrm{HR}=$ hazards ratio. ${ }^{a}$ Other factors included in the multivariate analysis were as follows: age (continuous), tumour grade (NHG I+II vs III), proliferation (Ki67 0-I, 2- I0, II - 25, $26-50,51-100 \%$ ), nodal status (negative vs positive) and tumour size ( $\leqslant 20$ vs

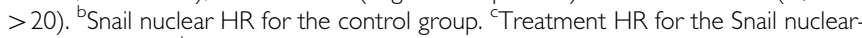
positive group. Interaction variable states whether there is a difference in the treatment response in relation to Snail nuclear status. increased cell migration that has previously been described for different cell lines as an effect of hypoxic exposure (Imai et al, 2003; Lester et al, 2007), was only observed for MDA-MB-468 cells. This suggests that these hypoxic breast cancer cells were only partially pushed towards EMT, with moderate increase in the E-cadherin repressor Snail. Accordingly, this partial induction is not sufficient to affect the migratory ability of these cell lines. Hypoxia is known to affect several factors involved in cell migration independently of EMT, and consequently the increased migratory capacity observed for hypoxic MDA-MB-468 cells did not seem to be an effect of increased Snail protein. The hypoxic response includes activation of numerous factors associated with cell motility and cytoskeletal structure (Semenza, 2003), and hence Snail-dependent migration is only one of several mechanism suggested to link hypoxia to an enhanced migratory propensity of tumour cells. The reduced migratory ability observed for MDAMB-231 cells exposed to hypoxia may also be due to hypoxic effects.

Subcellular localisation of Snail has been reported to be regulated by interaction with GSK-3 $\beta$, which predominantly resides in the cytoplasm (Zhou et al, 2004). Zhou et al (2004) demonstrated in MCF-7 cells that phosphorylation of Snail by
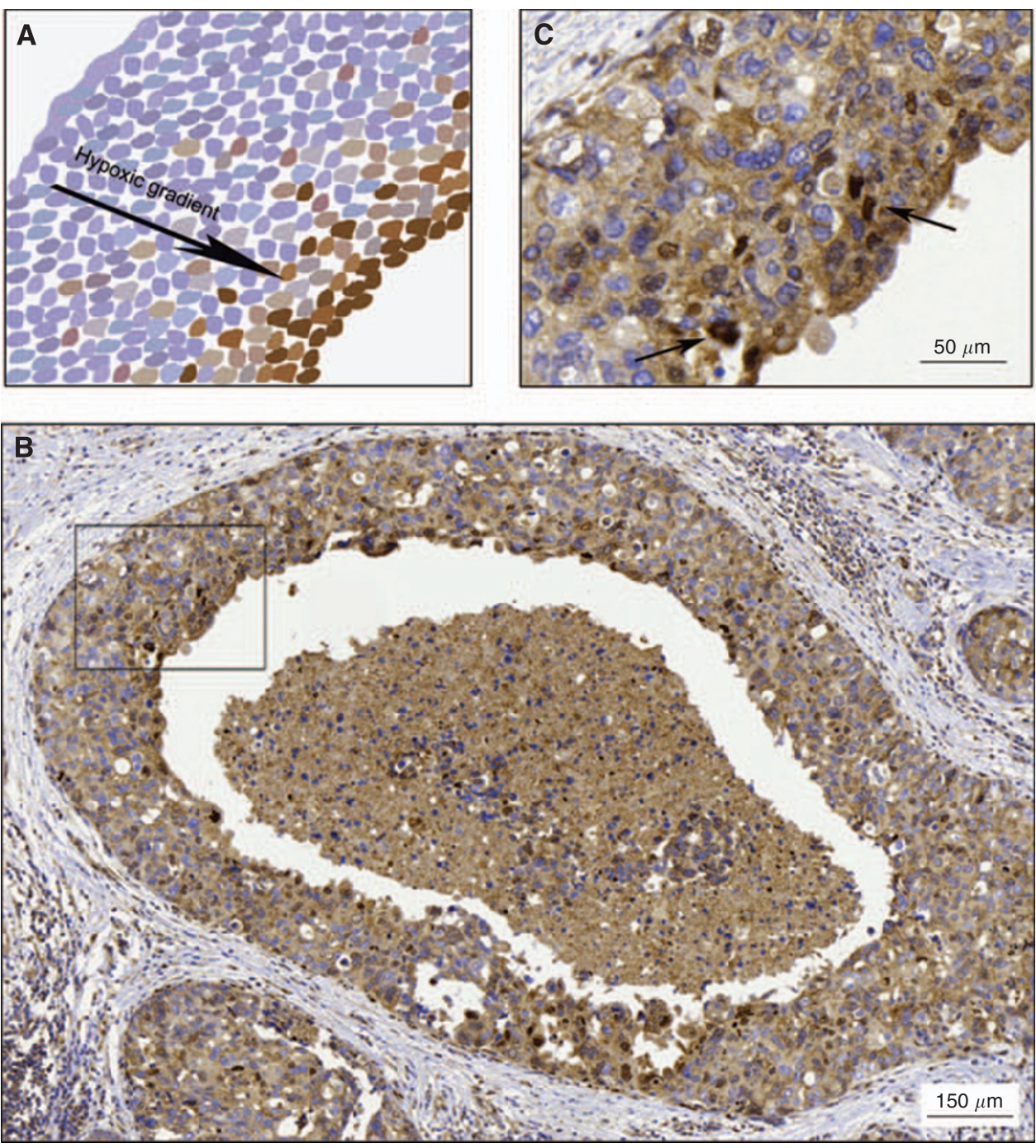

Figure 6 Immunohistochemical staining of Snail in DCIS. (A) A schematic representation of a typical HIF- I $\alpha$ staining appearance, with increasing staining intensity and number of positive cells approaching the central necrosis. (B) Nuclear expression of Snail was gradually increased in proximity to the central necrosis of DCIS. (C) Magnification $(\times 20)$ of the framed area in panel B. Arrows indicate cells with intense nuclear Snail staining. 
GSK-3 $\beta$ occurs at two different consensus motifs: the first resulting in targeting Snail for ubiquitination and the second regulating its subcellular localisation. A Snail mutant exhibiting mutations in these phosphorylation motifs was shown to be much more stable and resided exclusively in the nucleus, suggesting that only Snail that is unable to interact with and become phosphorylated by GSK$3 \beta$ is able to induce EMT in breast cancer cells. Interestingly, when screening for mutations in the two consensus motifs of Snail, no mutations could be identified, indicating that the upstream signalling is the crucial mechanism determining the function of Snail. Another protein that regulates the activity of Snail is the p21activated kinase 1 (Pak1) (Yang et al, 2005). Pak1 phosphorylation of Snail promotes nuclear accumulation and transcription repression activity of the E-cadherin gene in breast cancer cells, and hence induction of EMT (Yang et al, 2005). However, further studies are required to delineate the mechanism underlying nuclear, cytoplasmic shuttling and subcellular localisation of Snail.

In the present study we demonstrated that subcellular localisation of Snail changes over time in breast cancer cell lines exposed to hypoxia. In MCF-7 cells E-cadherin was hardly detectable after $72 \mathrm{~h}$, and expression of nuclear Snail was concurrently elevated, indicating that at this time point Snail was actively repressing E-cadherin-gene transcription in this cell line. Similarly, in MDAMB-468 and MDA-MB-231 cells nuclear expression levels of Snail peaked at $96 \mathrm{~h}$, around the same time that vimentin expression levels were markedly elevated in both cell lines. Nuclear expression of Snail did not increase as prominently in T-47D cells as in the other cell lines, which might explain the maintained levels of E-cadherin observed for this cell line. Our results indicate that hypoxia induces the expression of Snail, and after longer exposure Snail localises to the nucleus and exerts its EMT-inducing functions, resulting in downregulation of E-cadherin and upregulation of vimentin levels. The net result differs between cell lines, suggesting Snail to be more important as a regulator of EMT in some contexts, and may be inferior to other EMT regulators such as Slug or Twist in others.

The 'EMT status' of a cell line may not affect EMT regulation, that is, overexpression of Snail can induce a more migratory phenotype in both low-migratory, epithelial-like cell lines and in highly migratory, mesenchymal-like cell lines. The fact that Snail overexpression increased the migratory ability of both MCF-7 and T-47D cells, despite maintenance of E-cadherin expression in T-47D cells, suggests that E-cadherin expression does not exclude a migratory behaviour. The highly migratory MDA-MB-231 cells further increased their migratory capacity when overexpressing Snail, without exhibiting increased vimentin levels, further implying that Snail itself can drive migration independently of an EMT induction. Knocking down Snail resulted in significant reduction of the migratory capacity of MCF-7, MDA-MB-468 and MDA-MB-231 cells. The mechanism behind this shift in migration can again not be explained by regulation of E-cadherin or vimentin, since expression of neither of the two proteins was significantly changed by Snail silencing. Hence, another regulator of cell migration dependent or independent of EMT is possibly affected by Snail depletion. A plethora of factors play roles in the induction of EMT and regulating mechanisms generally differ between cell lines.

A number of studies describing Snail in breast cancer have been published, and the critical findings differ slightly among them. In one study Snail immunoreactivity was observed exclusively in the cytoplasm, contrasting to what is generally observed (Zhou et al, 2004), indicating antibody unreliability in this field of research. Becker et al (2007) reported $33 \%$ of breast cancers as being positive for nuclear Snail staining, similar to the $31 \%$ that we observed, using the same Snail antibody as in our study. Presence of nuclear Snail predicted a tumour phenotype displaying a more poorly differentiated histology and increased proliferation rate in premenopausal breast cancer, confirming the previously reported link between EMT and clinical aggressiveness (Cano et al, 2000; Blanco et al, 2002). Additionally, nuclear Snail protein was associated with more extensive hypoxia, defined by expression of the HIF- $1 \alpha$-inducible gene CAIX (Chaudary and Hill, 2006), implying a link between hypoxia and EMT in primary breast cancer. However, no correlation between Snail and HIF- $1 \alpha$ expression was observed. Cytoplasmic Snail expression was not associated with HIF- $1 \alpha$ or CAIX, or with any other clinicopathological variables, suggesting that expression of nuclear Snail plays the main role in determining the extent of clinical aggressiveness in breast cancer. A negative correlation between nuclear Snail and presence of $\mathrm{ER} \alpha$ was observed, and this inverse relationship has previously been reported with a number of breast tumour materials analysed by microarray (Dhasarathy et al, 2007). Moreover, Snail has been reported to directly repress ER $\alpha$-gene transcription in MCF-7 cells by binding to the promoter region (Dhasarathy et al, 2007). The ER-MTA3-E-cadherin pathway has emerged as a novel pathway in the regulation of ER signalling, and allelic alterations in these genes have been reported to be associated with both tumour-promoting and antitumour mechanisms (Cheng et al, 2001; Fearon, 2003). Furthermore, Snail suppresses the expression of the oestrogen-converting enzyme aromatase (Kumar, 2003), resulting in reduced levels of peripheral oestrogen converted from adipose tissue, which should be protective against breast cancer. The molecular function of Snail in breast epithelium is intricate and is further complicated by interaction with its downstream targets, such as the ER. Moreover, aetiological factors such as, for example, age at first full-term pregnancy, affects the importance of Snail as a susceptibility marker, and single-nucleotide polymorphism (SNP) of Snail has been shown to be of importance for the oestrogen-related risk factor in relation to breast cancer risk ( $\mathrm{Yu}$ et al, 2006). In one study it was demonstrated that $17 \beta$-estradiol $\left(\mathrm{E}_{2}\right)$ treatment, in an ER $\alpha$ mediated manner, resulted in increased metastatic potential, morphological changes characteristic of EMT and increased transcriptional activity of the Snail and Slug genes, accompanied by decreased levels of E-cadherin in an ovarian cancer cell line (Park et al, 2008). Silencing of either Snail or Slug caused reversion of the mesenchymal-like phenotype, and in addition treatment with the oestrogen antagonist ICI was shown to overcome the inhibitory effect of $\mathrm{E}_{2}$ on E-cadherin transcription, suggesting a crucial role for oestrogen and its receptor in EMT-dependent tumour progression. Interestingly, in the same study it was also demonstrated that presence of $\operatorname{ER} \beta$ had an opposing effect on $\operatorname{ER} \alpha$, in the context of EMT regulation, inhibiting the ER $\alpha$-induced EMT (Park et al, 2008). These findings may explain the mechanism by which ER status regulates invasion and metastasis in breast cancer. Nevertheless, the effect of oestrogen and the role of ER in the context of Snail and EMT regulation remain elusive. The fact that patients with Snail-negative tumours exhibited impaired tamoxifen response, as compared with treated patients with Snail-positive tumours in our study, is intriguing, but the underlying mechanism is yet to be elucidated. Speculatively, Snail may affect the function of $E R \alpha$ in a way that potentiates the effect of the ER antagonist tamoxifen. In tumours with nuclear Snail expression, tamoxifen might exert its effect by inhibiting the function of Snail, as described previously for the antagonist ICI. This in turn may lead to a less invasive tumour phenotype, since EMT is reverted. In Snail-negative tumours tamoxifen would not be able to exert the same mechanistic effect, resulting in an abolished response. Expression of $\operatorname{ER} \beta$ may also influence the mechanism that renders patients with Snail-negative tumours non-responsive to tamoxifen. Evidently, further studies including large randomised clinical cohorts are needed to investigate the role of Snail as a treatment predictive marker in breast cancer.

Moreover, in DCIS cells adjacent to the central necrosis exhibited nuclear Snail, further confirming an association between hypoxia and EMT. However, expression of E-cadherin and 
vimentin was not changed in areas with nuclear Snail staining, suggesting that Snail can be upregulated without affecting the expression of other EMT markers in vivo, as was also demonstrated in our breast cancer cell lines.

Our present study provides further evidence of the critical role of Snail in tumorigenic behaviour of breast cancer cell lines, and its association with clinicopathological parameters defining a more aggressive tumour phenotype. We demonstrate that breast cancer cells can enter a hybrid state of EMT, which is distinguished by partial mesenchymal conversion, where some hallmarks of EMT are present and others absent. Loss of E-cadherin expression is a well-established definition of invasiveness (Mayer et al, 1993; Oka et al, 1993). It has, however, been debated whether this definition is reliable or not (Christiansen and Rajasekaran, 2006). The expression of E-cadherin was reported in one study to be present in the majority of invasive breast carcinomas examined (Hashizume et al, 1996). Furthermore, node-negative and nodepositive tumours exhibited similar E-cadherin expression and no correlation between E-cadherin expression and metastatic status was observed. A number of additional reports show similar results regarding E-cadherin expression and tumour aggressiveness, implying that invasion is not necessarily dependent on a complete transition to a mesenchymal phenotype (Parker et al, 2001; Kovacs et al, 2003). Barrallo-Gimeno and co-workers argued that the primary function of Snail is to enhance cell movement, rather than to induce EMT (Barrallo-Gimeno and Nieto, 2005). In addition,
Lou et al (2008) reported that the metastatic ability was not linked to the EMT status. A cell line with expression of vimentin and lack of E-cadherin expression was unable to metastasise, whereas another cell line exhibiting epithelial characteristics was capable of metastasising. Accordingly, the question if a primary tumour will metastasise or not may not be determined by the EMT phenotype of the tumour cells. The expression of Snail itself may hold more information about a tumour's invasive capacity and ability to metastasise than the actual EMT status.

\section{ACKNOWLEDGEMENTS}

We thank Elise Nilsson for excellent technical implementation and Nicholas Tobin for contributions to the editing process. This study was supported by grants from the Swedish Cancer Society, Malmö University Hospital Research and Cancer Funds, South Swedish and South-East Swedish Breast Cancer groups and Breakthrough Breast Cancer, UK.

\section{Conflict of interest}

The authors declare no conflict of interest.

Supplementary Information accompanies the paper on British Journal of Cancer website (http://www.nature.com/bjc)

\section{REFERENCES}

Barrallo-Gimeno A, Nieto MA (2005) The Snail genes as inducers of cell movement and survival: implications in development and cancer. Development 132: $3151-3161$

Becker KF, Rosivatz E, Blechschmidt K, Kremmer E, Sarbia M, Hofler H (2007) Analysis of the E-cadherin repressor Snail in primary human cancers. Cells Tissues Organs 185: 204-212

Blanco MJ, Moreno-Bueno G, Sarrio D, Locascio A, Cano A, Palacios J, Nieto MA (2002) Correlation of Snail expression with histological grade and lymph node status in breast carcinomas. Oncogene 21: $3241-3246$

Brennan DJ, Jirstrom K, Kronblad A, Millikan RC, Landberg G, Duffy MJ, Ryden L, Gallagher WM, O'Brien SL (2006) CA IX is an independent prognostic marker in premenopausal breast cancer patients with one to three positive lymph nodes and a putative marker of radiation resistance. Clin Cancer Res 12: 6421-6431

Cano A, Perez-Moreno MA, Rodrigo I, Locascio A, Blanco MJ, del Barrio MG, Portillo F, Nieto MA (2000) The transcription factor snail controls epithelial-mesenchymal transitions by repressing E-cadherin expression. Nat Cell Biol 2: 76-83

Chaudary N, Hill RP (2006) Hypoxia and metastasis in breast cancer. Breast Dis 26: $55-64$

Cheng CW, Wu PE, Yu JC, Huang CS, Yue CT, Wu CW, Shen CY (2001) Mechanisms of inactivation of E-cadherin in breast carcinoma: modification of the two-hit hypothesis of tumor suppressor gene. Oncogene 20: 3814-3823

Christiansen JJ, Rajasekaran AK (2006) Reassessing epithelial to mesenchymal transition as a prerequisite for carcinoma invasion and metastasis. Cancer Res 66: 8319-8326

Dhasarathy A, Kajita M, Wade PA (2007) The transcription factor snail mediates epithelial to mesenchymal transitions by repression of estrogen receptor-alpha. Mol Endocrinol 21: $2907-2918$

Fearon ER (2003) Connecting estrogen receptor function, transcriptional repression, and E-cadherin expression in breast cancer. Cancer Cell 3: $307-310$

Flint D, Allan G, Beattie J (2008) Epithelial injury induces an innate repair mechanism linked to cellular senescence and fibrosis involving insulinlike growth factor binding protein -5. J Endocrinol 199(2): 155-164

Hajra KM, Chen DY, Fearon ER (2002) The SLUG zinc-finger protein represses E-cadherin in breast cancer. Cancer Res 62: 1613-1618

Harris AL (2002) Hypoxia - a key regulatory factor in tumour growth. Nat Rev Cancer 2: $38-47$
Hashizume R, Koizumi H, Ihara A, Ohta T, Uchikoshi T (1996) Expression of beta-catenin in normal breast tissue and breast carcinoma: a comparative study with epithelial cadherin and alpha-catenin. Histopathology 29: 139-146

Helczynska K, Kronblad A, Jogi A, Nilsson E, Beckman S, Landberg G, Pahlman S (2003) Hypoxia promotes a dedifferentiated phenotype in ductal breast carcinoma in situ. Cancer Res 63: 1441-1444

Imai T, Horiuchi A, Wang C, Oka K, Ohira S, Nikaido T, Konishi I (2003) Hypoxia attenuates the expression of E-cadherin via upregulation of SNAIL in ovarian carcinoma cells. Am J Pathol 163: $1437-1447$

Jirstrom K, Ryden L, Anagnostaki L, Nordenskjold B, Stal O, Thorstenson S, Chebil G, Jonsson PE, Ferno M, Landberg G (2005) Pathology parameters and adjuvant tamoxifen response in a randomised premenopausal breast cancer trial. J Clin Pathol 58: 1135-1142

Kovacs A, Dhillon J, Walker RA (2003) Expression of P-cadherin, but not Ecadherin or N-cadherin, relates to pathological and functional differentiation of breast carcinomas. Mol Pathol 56: 318-322

Kronblad A, Jirstrom K, Ryden L, Nordenskjold B, Landberg G (2006) Hypoxia inducible factor-1alpha is a prognostic marker in premenopausal patients with intermediate to highly differentiated breast cancer but not a predictive marker for tamoxifen response. Int J Cancer 118: $2609-2616$

Kumar R (2003) Another tie that binds the MTA family to breast cancer Cell 113: $142-143$

Kurrey NK, K A, Bapat SA (2005) Snail and Slug are major determinants of ovarian cancer invasiveness at the transcription level. Gynecol Oncol 97: $155-165$

Lester RD, Jo M, Montel V, Takimoto S, Gonias SL (2007) uPAR induces epithelial-mesenchymal transition in hypoxic breast cancer cells. J Cell Biol 178: $425-436$

Liotta LA, Kohn EC (2001) The microenvironment of the tumour-host interface. Nature 411: 375-379

Lou Y, Preobrazhenska O, auf dem Keller U, Sutcliffe M, Barclay L, McDonald PC, Roskelley C, Overall CM, Dedhar S (2008) Epithelialmesenchymal transition (EMT) is not sufficient for spontaneous murine breast cancer metastasis. Dev Dyn 237: $2755-2768$

Matter K, Balda MS (2003) Signalling to and from tight junctions. Nat Rev Mol Cell Biol 4: 225-236

Mayer B, Johnson JP, Leitl F, Jauch KW, Heiss MM, Schildberg FW, Birchmeier W, Funke I (1993) E-cadherin expression in primary and 
metastatic gastric cancer: down-regulation correlates with cellular dedifferentiation and glandular disintegration. Cancer Res 53: 1690 - 1695

Moody SE, Perez D, Pan TC, Sarkisian CJ, Portocarrero CP, Sterner CJ, Notorfrancesco KL, Cardiff RD, Chodosh LA (2005) The transcriptional repressor Snail promotes mammary tumor recurrence. Cancer Cell 8: $197-209$

Oka H, Shiozaki H, Kobayashi K, Inoue M, Tahara H, Kobayashi T, Takatsuka Y, Matsuyoshi N, Hirano S, Takeichi M, Mori T (1993) Expression of E-cadherin cell adhesion molecules in human breast cancer tissues and its relationship to metastasis. Cancer Res 53: 1696-1701

Olmeda D, Jorda M, Peinado H, Fabra A, Cano A (2007) Snail silencing effectively suppresses tumour growth and invasiveness. Oncogene 26: $1862-1874$

Park SH, Cheung LW, Wong AS, Leung PC (2008) Estrogen regulates Snail and Slug in the down-regulation of E-cadherin and induces metastatic potential of ovarian cancer cells through estrogen receptor alpha. Mol Endocrinol 22: 2085-2098

Parker C, Rampaul RS, Pinder SE, Bell JA, Wencyk PM, Blamey RW, Nicholson RI, Robertson JF (2001) E-cadherin as a prognostic indicator in primary breast cancer. $\mathrm{Br}$ J Cancer 85: $1958-1963$

Peinado H, Olmeda D, Cano A (2007) Snail, Zeb and bHLH factors in tumour progression: an alliance against the epithelial phenotype? Nat Rev Cancer 7: 415-428

Ryden L, Jonsson PE, Chebil G, Dufmats M, Ferno M, Jirstrom K, Kallstrom AC, Landberg G, Stal O, Thorstenson S, Nordenskjold B (2005) Two years of adjuvant tamoxifen in premenopausal patients with breast cancer: a randomised, controlled trial with long-term follow-up. Eur J Cancer 41: $256-264$
Semenza GL (2002) HIF-1 and tumor progression: pathophysiology and therapeutics. Trends Mol Med 8: S62-S67

Semenza GL (2003) Targeting HIF-1 for cancer therapy. Nat Rev Cancer 3: $721-732$

Sleeman JP (2000) The lymph node as a bridgehead in the metastatic dissemination of tumors. Recent Results Cancer Res 157: 55-81

Thiery JP (2003) Epithelial-mesenchymal transitions in development and pathologies. Curr Opin Cell Biol 15: $740-746$

Thiery JP, Sleeman JP (2006) Complex networks orchestrate epithelialmesenchymal transitions. Nat Rev Mol Cell Biol 7: 131-142

Vaupel P, Briest S, Hockel M (2002) Hypoxia in breast cancer: pathogenesis, characterization and biological/therapeutic implications. Wien Med Wochenschr 152: 334-342

Yang MH, Wu KJ (2008) TWIST activation by hypoxia inducible factor-1 (HIF-1): implications in metastasis and development. Cell Cycle 7: $2090-2096$

Yang Z, Rayala S, Nguyen D, Vadlamudi RK, Chen S, Kumar R (2005) Pak1 phosphorylation of snail, a master regulator of epithelial-to-mesenchyme transition, modulates snail's subcellular localization and functions. Cancer Res 65: 3179-3184

Yu JC, Hsu HM, Chen ST, Hsu GC, Huang CS, Hou MF, Fu YP, Cheng TC, Wu PE, Shen CY (2006) Breast cancer risk associated with genotypic polymorphism of the genes involved in the estrogen-receptor-signaling pathway: a multigenic study on cancer susceptibility. J Biomed Sci 13: $419-432$

Zhou BP, Deng J, Xia W, Xu J, Li YM, Gunduz M, Hung MC (2004) Dual regulation of Snail by GSK-3beta-mediated phosphorylation in control of epithelial-mesenchymal transition. Nat Cell Biol 6: 931 -940 